\title{
Sugar and total energy content of household food purchases in Brazil
}

\author{
Renata Bertazzi Levy ${ }^{1,2}$, Rafael Moreira Claro ${ }^{2}$ and Carlos Augusto Monteiro 2,3,* \\ ${ }^{1}$ Núcleo de Investigação em Nutrição, Instituto de Saúde, Secretaria do Estado de Saúde de São Paulo \\ (IS/SES), São Paulo, Brazil: ${ }^{2}$ Núcleo de Pesquisas Epidemiológicas em Nutrição e Saúde, Universidade de \\ São Paulo (NUPENS/USP), São Paulo, Brazil: ${ }^{3}$ Departamento de Nutrição, Faculdade de Saúde Pública, \\ Universidade de São Paulo (USP), Av. Dr Arnaldo 715, $2^{\circ}$ andar, CEP 01246-904, São Paulo, SP, Brazil
}

Submitted 26 August 2008: Accepted 26 February 2009: First published online 30 April 2009

\begin{abstract}
Objective: To study the role of energy derived from sugar (both table sugar and sugar added to processed foods) in the total energy content of food purchases in Brazil.

Design: Food purchase data were collected during a national household budget survey carried out between June 2002 and July 2003 on a probabilistic sample representative of all households in the country. The amount of food purchased in this 12-month period was transformed into energy and energy from sugar using food composition tables. Multiple linear regression models were used to study the association between amount of energy from sugar and total energy content of food purchases, controlling for sociodemographic variables and potential interactions between these variables and sugar purchases.

Results: There was a positive and significant association between energy from sugar and total household energy purchases. A $1 \mathrm{~kJ}$ increase in sugar purchase corresponded to a $3.637 \mathrm{~kJ}$ increase in total energy. In the absence of expenditure on meals outside the home, i.e. when household food purchases tend to approximate actual food consumption by household members, sugar purchase of $1926.35 \mathrm{~kJ} / \mathrm{d}$ (the 90 th percentile of the distribution of sugar purchases in Brazil) was associated, depending on income strata, with total energy purchase over $40-60 \%$ of the recommended daily value for energy intake in Brazil.

Conclusions: The present results corroborate the recommendations of the WHO and the Brazilian Ministry of Health regarding limiting the consumption of sugar.
\end{abstract}

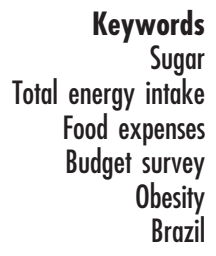

Demographic and economic changes are accelerating across the globe, and particularly in developing countries. Such changes have an especially marked effect on diet composition. Noteworthy among these effects is the increased consumption of sugar (both table sugar and sugar added by the processed food industry) and fat, along with the decrease in consumption of complex carbohydrates $^{(1)}$. An analysis of global food availability showed that the per capita availability of sugar increased by $32 \%$ between 1962 and 2000 (corresponding to a daily increase of $315 \mathrm{~kJ}$ ). Urbanization and increased income are thought to account for $82 \%$ of the increase in sugar intake, the remainder being attributed to factors related to changes in consumer behaviour and/or expansion of the food industry ${ }^{(2)}$. In the USA, per capita sugar intake among the population older than 2 years of age increased by $349 \mathrm{~kJ} / \mathrm{d}$ between 1977 and 2000, which raised by $22 \%$ the contribution of sugar to the total energy content of the diet in this population (from $13 \cdot 0 \%$ to $15 \cdot 8 \%$ ). Of this increase, $227 \mathrm{~kJ}$ corresponded to soft drinks and $55 \mathrm{~kJ}$ to sweetened fruit juice. Among adolescents, there was an increase in the intake of soft drinks at the expense of milk ${ }^{(2)}$.

Brazil is the biggest sugar producer in the world, with an annual production of $26 \cdot 4$ million tonnes (raw sugar equivalent) in 2003. In this same year, the per capita availability of sugar in Brazil was $2310 \mathrm{~kJ} / \mathrm{d}$, which corresponded to $17 \cdot 5 \%$ of total energy available for consumption. This high contribution of sugar to the total food supply, one of the highest in the world, has remained almost unchanged since the early $1960 \mathrm{~s}^{(3)}$.

The potential health hazards associated with increased sugar intake and the maximum limits for its contribution to the diet have been the object of intense debate in national and international forums ${ }^{(1,4,5)}$. The WHO and the FAO claim there is convincing evidence that excessive sugar intake increases the risk of at least two important public health problems: obesity (via increased energy intake) and dental caries. Based on this evidence, these 
agencies recommend that the contribution of sugar not exceed $10 \%$ of total energy in a $\operatorname{diet}^{(1)}$. On the other hand, the Institute of Medicine, a non-governmental organization responsible for elaborating dietary guidelines for the American and Canadian populations, believes the dilution of micronutrients to be the only proven negative effect of sugar intake, and that this effect can only be felt when the contribution of sugar in the diet exceeds $25 \%$ of total energy intake ${ }^{(5)}$.

Sugar intake can influence total energy intake through hedonic and physiological mechanisms. Owing to its organoleptic properties, sugar intake triggers a strong sensation of pleasure ${ }^{(6)}$. In physiological terms, the ingestion of sugar leads to a rapid increase in blood glucose, which is followed by the release of high amounts of insulin, leading to the reduction of blood glucose to levels below normal. Low blood glucose leads to a feeling of hunger, and thus may result in excessive energy intake $^{(7)}$. Furthermore, high sugar content may lead to highly energy-dense diets, which once more can give rise to excessive energy intake ${ }^{(8,9)}$. Other studies suggest that ingestion of sweetened beverages increases the total energy content of the diet by limiting appetite-control mechanisms and provoking a reduction in the compensatory effect of food intake ${ }^{(10-13)}$.

Population-based studies on the effects of sugar intake on total energy intake are scarce and usually are restricted to developed countries ${ }^{(2,14)}$. The present paper uses data from a national household budget survey conducted in Brazil in 2002-3 to study the role of energy derived from sugar (both table sugar and sugar added to processed foods) in the total energy content of food purchases in Brazil.

\section{Methods}

All data analysed in the current study originate from the Household Budget Survey carried out by the Brazilian Institute of Geography and Statistics between June 2002 and July 2003 (2002-3 HBS) using a representative sample of all Brazilian households. As explained below, the data collected in this survey describe in great detail all food purchases made by families throughout a 12-month period, thus providing simultaneous estimates for the two variables that we shall attempt to correlate: energy from sugar and total energy content of food purchases.

\section{Sampling}

The 2002-3 HBS was designed so as to represent the totality of Brazilian households and urban or rural households from each of the twenty-six Brazilian states. This sample was stratified and randomized in two stages. The 443 sample strata were formed by grouping census tracts homogeneous with respect to territorial domain (states), urban or rural settings and average household socio-economic characteristics. Selection of census tracts (primary sampling unit) within each stratum was done by systematic sampling with probability proportional to the number of households in the tract. Household selection (secondary sampling unit) within each sector was done by simple random selection without reposition. In order for data collection to be uniform throughout the year's four trimesters, interviews carried out within each of the 443 strata were distributed throughout the 12 months of survey. From 60911 households selected in 3984 tracts, a total of 48470 , or $79 \cdot 6 \%$, were effectively investigated.

The reference period for collecting information on food purchases in individual households in the 2002-3 HBS was only $7 \mathrm{~d}$. As such a short reference period does not allow for an adequate characterization of the food purchasing patterns of each household, the unit of analysis in the present study is the set of studied households in each of the sample's 443 strata, rather than the individual household. The mean number of households in each of these strata was $109 \cdot 6$, ranging from 9 to 804 . The weighting factor for each stratum was defined as the sum of the weighting factors of all households included in the stratum.

\section{Data collection}

Information on food items purchased by each household was obtained using the survey's collective expense notebook. In this notebook, household members recorded all food purchases made during seven consecutive days, including amount, purchase unit with its equivalent weight or volume, amount paid, place of purchase, and how the food was obtained. In about $75 \%$ of households, daily purchase data recorded in the notebook were registered electronically by the survey interviewer using a portable computer, thus allowing for information consistency to be verified and errors to be corrected while still in the household.

\section{Variable construction}

The central variables in the present study are total energy purchased by the households in each of the survey's strata and the energy derived from sugar. In the latter case, we considered both table sugar and sugar added by the processed food industry. Rapadura (hardened sugar cane extract), molasses, honey and other caloric sweeteners, even though accounting for a minute fraction of the total energy purchased by Brazilian families, were also considered in the calculation of energy from sugar. Intrinsic sugar present in food, such as fructose and sucrose in fruits, was regarded as part of the remaining energy not provided by sugar. The procedures employed for obtaining these variables were as follows: (i) addition of the amounts of the same food (in grams) purchased in the $7 \mathrm{~d}$ period; (ii) use of a correction factor for each food type that considers only its edible portion ${ }^{(15)}$; (iii) conversion of the purchased amount of each food into total energy and energy from sugar, using the TACO chart 
(Brazilian Food Composition Table) ${ }^{(16)}$ or the US official food composition table version $15^{(17)}$ for the few items not present in TACO. In the specific case of conversion to energy from sugar, calculation was done in two stages: conversion of quantities (in grams) into energy from carbohydrates (using TACO whenever possible) and conversion of energy from carbohydrates into energy from sugar (using the American chart, as TACO does not specify the types of carbohydrates in each food); and (iv) addition of total energy and energy from sugar purchased from all households in the same stratum and division by the number of adult equivalents (AE) existing in the stratum (the weighting factors for each household were employed at this stage). The AE were obtained by dividing the Recommended Dietary Allowance (RDA) for each age-gender group by the average RDA for energy for an adult $(10710 \mathrm{~kJ})$. Individual $\mathrm{AE}$ of each household were added to obtain an AE for each stratum ${ }^{(18)}$.

The sociodemographic attributes of each stratum were used to characterize the study units and to control for potential confounder effects on the association between energy from sugar and total energy content of the household food purchase. These attributes included location (North, North-east, South-east, South or Centre-West macro regions) and urban or rural status of the household, in addition to mean per capita household income, proportion of total food expenditure dedicated to meals outside the home, and percentage of members under 20 years, over 64 years and of female gender. In order to arrive at these mean values, we once again employed the weighting factors for each household in the stratum.

\section{Data analysis}

The crude relationship between energy from sugar and total energy content of all household food purchases was first described by calculating daily mean adult equivalent energy availability according to quartile of energy purchased from sugar.

The association between energy from sugar and total energy content of all household food purchases, adjusted for confounding variables, was determined by multiple linear regression models using as dependent variable the total energy from all food purchases. In addition to energy from sugar (explanatory variable), we introduced in the models all variables showing $P$ values below $0 \cdot 20$ in bivariate linear regression models for the association with total energy or energy from sugar (potential confounders). We used a backward modelling strategy, removing potential confounders from the 'saturated model' in a stepwise fashion, beginning with the factor with the highest $P$ value. Variables that altered the magnitude of the regression coefficient for the effect of energy from sugar on total energy by at least 5\% were kept in the final model. In addition, we investigated the potential effects of interactions between energy from sugar and confounding variables on total energy, keeping in the final model all significant interactions $(P<0 \cdot 05)$. In order to provide a visual representation of the effects of interactions on total energy, we plotted graphs representing different scenarios with respect to the variables involved in significant interactions.

The adequacy of the final regression models was tested by residual analysis. In all analyses included in the present study, we employed weighting factors to allow for extrapolation of our results to the Brazilian population. All analyses were performed with the aid of STATA Special Edition statistical software package, version 8.0 (Stata Corporation, College Station, TX, USA).

\section{Results}

Table 1 shows a monotonic and significant increase in total energy purchased by Brazilian families as sugar purchases increased, indicating a difference of over $3780 \mathrm{~kJ} / \mathrm{AE}$ per $\mathrm{d}$ among the $25 \%$ that consumed the least and the $25 \%$ that consumed the most sugar. The table also shows that the increase in total energy content is well above that expected if the increase in total energy were due to an increase in sugar purchases alone.

Table 2 shows that all sociodemographic variables investigated were associated with total energy content or with sugar intake at a statistically relevant level $(P<0 \cdot 20)$. These variables were therefore considered as potential confounders in the association between sugar intake and total energy content.

Table 3 presents the results of the final multiple regression model for total energy purchased by the household including, in addition to energy from sugar, all of the sociodemographic confounders whose removal

Table 1 Total energy content from all food purchases according to amount of sugar purchased, Brazil, 2002-3

\begin{tabular}{|c|c|c|c|}
\hline \multirow[b]{2}{*}{ Quartile of sugar purchase (kJ/AE per d) } & \multicolumn{2}{|c|}{ All food purchases (kJ/AE per d) } & \multirow[b]{2}{*}{$P$} \\
\hline & Mean & SE & \\
\hline $1(42 \cdot 4-1097 \cdot 0)$ & $6693 \cdot 54$ & $179 \cdot 34$ & $<0.001^{*}$ \\
\hline $2(1097 \cdot 9-1360 \cdot 0)$ & $7987 \cdot 56$ & $138 \cdot 18$ & \\
\hline $3(1362 \cdot 9-1565 \cdot 8)$ & $8883 \cdot 84$ & $161 \cdot 70$ & \\
\hline $4(1566 \cdot 2-3723 \cdot 7)$ & $10711 \cdot 26$ & $426 \cdot 72$ & \\
\hline Total $(42 \cdot 4-3723 \cdot 7)$ & $8558 \cdot 34$ & $158 \cdot 34$ & \\
\hline
\end{tabular}

$\mathrm{AE}$, adult equivalent.

${ }^{\star} P$ for linear trend. 
Table 2 Mean energy from all food purchases and mean energy from sugar purchases according to sociodemographic variables, Brazil, 2002-3

\begin{tabular}{|c|c|c|c|c|}
\hline Variable & $\begin{array}{l}\text { All food purchases } \\
\text { (kJ/AE per d) }\end{array}$ & $P$ & $\begin{array}{l}\text { Sugar purchases } \\
(\mathrm{kJ} / \mathrm{AE} \text { per } \mathrm{d})\end{array}$ & $P$ \\
\hline Region & & 0.859 & & 0.007 \\
\hline North & $9020 \cdot 7$ & & $1077 \cdot 3$ & \\
\hline North-east & $8421 \cdot 8$ & & $1307 \cdot 9$ & \\
\hline South-east & $8392 \cdot 0$ & & $1440 \cdot 6$ & \\
\hline South & $9274 \cdot 0$ & & 1433.5 & \\
\hline Centre-West & $8072 \cdot 0$ & & $1274 \cdot 7$ & \\
\hline Area & & $<0.001$ & & $<0.001$ \\
\hline Urban & $8056 \cdot 0$ & & $1304 \cdot 9$ & \\
\hline Rural & $11349 \cdot 7$ & & $1735 \cdot 0$ & \\
\hline Per capita family income $(\mathrm{R} \$)^{*}$ & & $0.001 \dagger$ & & $0 \cdot 129+$ \\
\hline $67 \cdot 8-381 \cdot 3$ & $8691 \cdot 1$ & & $1325 \cdot 5$ & \\
\hline $382 \cdot 2-493 \cdot 3$ & $9398 \cdot 3$ & & $1541 \cdot 4$ & \\
\hline $493 \cdot 8-725 \cdot 2$ & $8170 \cdot 3$ & & $1337 \cdot 7$ & \\
\hline $730 \cdot 7-4562 \cdot 2$ & $7968 \cdot 7$ & & $1276 \cdot 4$ & \\
\hline Total food expenditures on meals outside the home $(\%)^{*}$ & & $<0.001 \dagger$ & & $<0.001 \dagger$ \\
\hline $1 \cdot 7-18 \cdot 4$ & $10116 \cdot 1$ & & $1518 \cdot 7$ & \\
\hline $18 \cdot 5-20 \cdot 1$ & $8564 \cdot 2$ & & $1423 \cdot 4$ & \\
\hline $20 \cdot 2-25 \cdot 7$ & $8087 \cdot 5$ & & $1370 \cdot 0$ & \\
\hline $25 \cdot 8-73 \cdot 5$ & $7460 \cdot 0$ & & $1168 \cdot 9$ & \\
\hline Under 20 years $(\%)^{*}$ & & $0.993+$ & & $0 \cdot 175 t$ \\
\hline $3 \cdot 6-30 \cdot 2$ & $8704 \cdot 9$ & & 1383.5 & \\
\hline $30 \cdot 3-36 \cdot 4$ & $8411 \cdot 8$ & & $1418 \cdot 3$ & \\
\hline $36 \cdot 5-40 \cdot 3$ & $8402 \cdot 9$ & & $1413 \cdot 3$ & \\
\hline $40 \cdot 4-61 \cdot 8$ & $8714 \cdot 2$ & & $1265 \cdot 9$ & \\
\hline Over 64 years $(\%)^{*}$ & & $<0.001 \dagger$ & & $<0.001 \dagger$ \\
\hline $0 \cdot 0-6 \cdot 8$ & $7482 \cdot 7$ & & $1106 \cdot 3$ & \\
\hline $6 \cdot 9-8 \cdot 6$ & $8516 \cdot 8$ & & $1381 \cdot 0$ & \\
\hline $8 \cdot 7-9 \cdot 7$ & $9114 \cdot 0$ & & $1537 \cdot 2$ & \\
\hline $9 \cdot 8-20 \cdot 6$ & 9133.3 & & $1459 \cdot 9$ & \\
\hline Women $(\%)^{*}$ & & $<0.001 \dagger$ & & $0.006+$ \\
\hline $39 \cdot 9-50 \cdot 3$ & 9775.9 & & $1503 \cdot 2$ & \\
\hline $50 \cdot 4-50 \cdot 9$ & $8284 \cdot 1$ & & 1336.9 & \\
\hline $51 \cdot 0-52 \cdot 0$ & $8278 \cdot 2$ & & $1407 \cdot 8$ & \\
\hline $52 \cdot 1-67 \cdot 0$ & $7871 \cdot 2$ & & $1233 \cdot 1$ & \\
\hline Total & $8558 \cdot 3$ & & 1370.5 & \\
\hline
\end{tabular}

$A E$, adult equivalent.

*Variable intervals correspond to quartiles of the variable distribution.

$+P$ for linear trend.

Table 3 Results of the final multiple linear regression model (without interactions) on the total energy content of all household food purchases (kJ/AE per d), Brazil, 2002-3

\begin{tabular}{lcc}
\hline Variables in the model & Regression coefficient & $95 \% \mathrm{Cl}$ \\
\hline & & $R^{2}$ \\
Energy from sugar (kJ/AE per d) & $3 \cdot 637$ & $3 \cdot 122,4 \cdot 153$ \\
Household income (log R \$/person) & $772 \cdot 846$ & $465 \cdot 259,1080 \cdot 442$ \\
Percentage of total food expenditures on meals outside the home & $-50 \cdot 232$ & $-77 \cdot 263,-23 \cdot 201$ \\
Area (0 = urban, 1 = rural) & $1656 \cdot 035$ & $1088 \cdot 665,2223 \cdot 400$ \\
Region & & \\
$\quad$ North & & $-1894 \cdot 015,-841 \cdot 697$ \\
North-east & $-1367 \cdot 856$ & $-2462 \cdot 216,-1410 \cdot 070$ \\
South-east & $-1936 \cdot 141$ & $-1889 \cdot 887,-654 \cdot 242$ \\
$\quad$ South & $-1272 \cdot 062$ & $-2195 \cdot 143,-1090 \cdot 740$ \\
$\quad$ Centre-West & $-1642 \cdot 943$ & \\
\hline
\end{tabular}

$A E$, adult equivalent.

modified by at least 5\% the regression coefficient associated with energy from sugar. This model was able to 'explain' over two-thirds of the variability in total energy purchased by the household $\left(R^{2}=0 \cdot 761\right)$. In constructing the model, we tested different transformations for the income variable, with logarithmic transformation yielding the best fit. In the case of sugar, the best fit was obtained without variable transformation.

The estimated regression coefficient for energy from sugar $(3 \cdot 637 ; 95 \%$ CI $3 \cdot 122,4 \cdot 153)$ implies that each additional kilojoule from sugar was associated with an increase of over three-and-a-half kilojoules in the total 
Table 4 Results of the final multiple linear regression model (with interactions) on the total energy content of all household food purchases (kJ/AE per d), Brazil, 2002-3

\begin{tabular}{|c|c|c|c|}
\hline Variable in the model & $\begin{array}{l}\text { Regression } \\
\text { coefficient }\end{array}$ & $95 \% \mathrm{Cl}$ & $R^{2}$ \\
\hline & & & 0.789 \\
\hline Energy from sugar (kJ/AE per d) & $-2 \cdot 611$ & $-6 \cdot 111,0 \cdot 889$ & \\
\hline Household income (log R\$/person) & $-1812 \cdot 523$ & $-2777 \cdot 305,-847 \cdot 745$ & \\
\hline Percentage of total food expenditures on meals outside the home & $-82 \cdot 551$ & $-207 \cdot 110,42 \cdot 013$ & \\
\hline Area $(0=$ urban $1=$ rural $)$ & $1206 \cdot 400$ & $666 \cdot 023,1746 \cdot 776$ & \\
\hline \multirow{2}{*}{\multicolumn{4}{|c|}{ Region }} \\
\hline & & & \\
\hline North-east & $-1221 \cdot 692$ & $-1754 \cdot 785,-688 \cdot 603$ & \\
\hline South-east & $-1685 \cdot 817$ & $-2207 \cdot 268,-1164 \cdot 366$ & \\
\hline South & $-1070 \cdot 336$ & $-1693 \cdot 810,-446 \cdot 863$ & \\
\hline Centre-West & $-1458 \cdot 702$ & $-2027 \cdot 407,-889 \cdot 997$ & \\
\hline Energy from sugar $\times$ Household income & $6 \cdot 161$ & $3 \cdot 714,8 \cdot 607$ & \\
\hline Energy from sugar $\times$ Percentage of total food expenditures on meals outside the home & -0.533 & $-0.710,-0.353$ & \\
\hline Household income $\times$ Percentage of total food expenditures with on outside the home & $27 \cdot 959$ & $11 \cdot 847,44 \cdot 071$ & \\
\hline
\end{tabular}

$\mathrm{AE}$, adult equivalent.

energy household purchases. In other words, purchasing an additional $1 \mathrm{~kJ}$ of sugar leads to the purchase of an 'extra' $2.637 \mathrm{~kJ}$ derived from other macronutrients that are not sugar (fats, proteins or other carbohydrates). As expected, a regression coefficient of $2.637 \mathrm{~kJ} / \mathrm{AE}$ per $\mathrm{d}$ was found using a linear regression model identical to that presented in Table 3, but using as a dependent variable total energy purchases excluding energy from sugar (data not shown).

Additional analyses departing from the final multiple regression model showed three significant interactions, between: (i) energy from sugar and family income; (ii) energy from sugar and percentage of total food expenditures on meals outside the home; and (iii) family income and percentage of total food expenditures on meals outside the home. Table 4 shows the results of the final regression model including the effects of these interactions on total energy purchases $\left(R^{2}=0 \cdot 789\right)$.

In order for the interaction effects to be more easily visualized, we present three graphs (Figs 1a to 1c) that consider different scenarios in terms of family income and expenditure on meals outside the home. These graphs show the variation in the amount of energy from sugar purchased between a minimum corresponding to the 10th centile of the distribution of sugar purchases in the total household sample of the 2002-3 HBS and a maximum corresponding to the 90th centile of the same distribution. Income is fixed in each of the three graphs at values equivalent, respectively, to the lower, middle and upper quintile of the family income distribution. In each of the three graphs, we present the relationship between energy from sugar and total energy without fixing the percentage of total food expenditures on meals outside the home, as well as under the condition of absence of expenditure on meals outside the home.

In the three income scenarios, increases in sugar purchases are associated with an increase in total energy purchases, which are, as expected, always higher for no expenditure on meals outside the home. Particularly relevant are the predictions regarding total energy with no expenditure on meals outside the home since, under this condition, the household food purchase would tend to be closer to the actual energy intake of household members. Under the condition of zero expenditure on meals outside the home, purchasing an amount of sugar corresponding to the 90th centile of the distribution of sugar purchasing in the country $(1926.35 \mathrm{~kJ} / \mathrm{AE}$ per d) would be associated with a total energy purchase of $13136 \mathrm{~kJ} / \mathrm{AE}$ per $\mathrm{d}$ in low-income households (lower quintile), $14074 \mathrm{~kJ} / \mathrm{AE}$ per $\mathrm{d}$ in intermediate-income households (middle quintile) and $15172 \mathrm{~kJ} / \mathrm{AE}$ per $\mathrm{d}$ in high-income households (upper quintile).

We also tested independent models for urban and rural households. Differences between these models and that contemplating the entire sample were only slight, and therefore these data are not presented.

\section{Discussion}

Based on a probabilistic survey representative of the totality of Brazilian households, the present study has shown evidence of a positive and significant association between energy from sugar and the total energy content of all household food purchases: a $1 \mathrm{~kJ}$ increase in sugar purchases corresponded to a $3.637 \mathrm{~kJ}$ increase in total energy. In other words, purchasing an additional $1 \mathrm{~kJ}$ of sugar leads to the purchase of an 'extra' $2 \cdot 637 \mathrm{~kJ}$ derived from other macronutrients that are not sugar (fats, proteins or other carbohydrates). Under the condition of an absence of expenditure on meals outside the home, and therefore given a scenario in which household food purchases would tend to approximate the actual food consumption of household members, a sugar purchase of $1926 \cdot 35 \mathrm{~kJ} / \mathrm{AE}$ per $d$ (the 90th centile of the distribution of sugar purchasing in Brazil) would be associated, across all income 

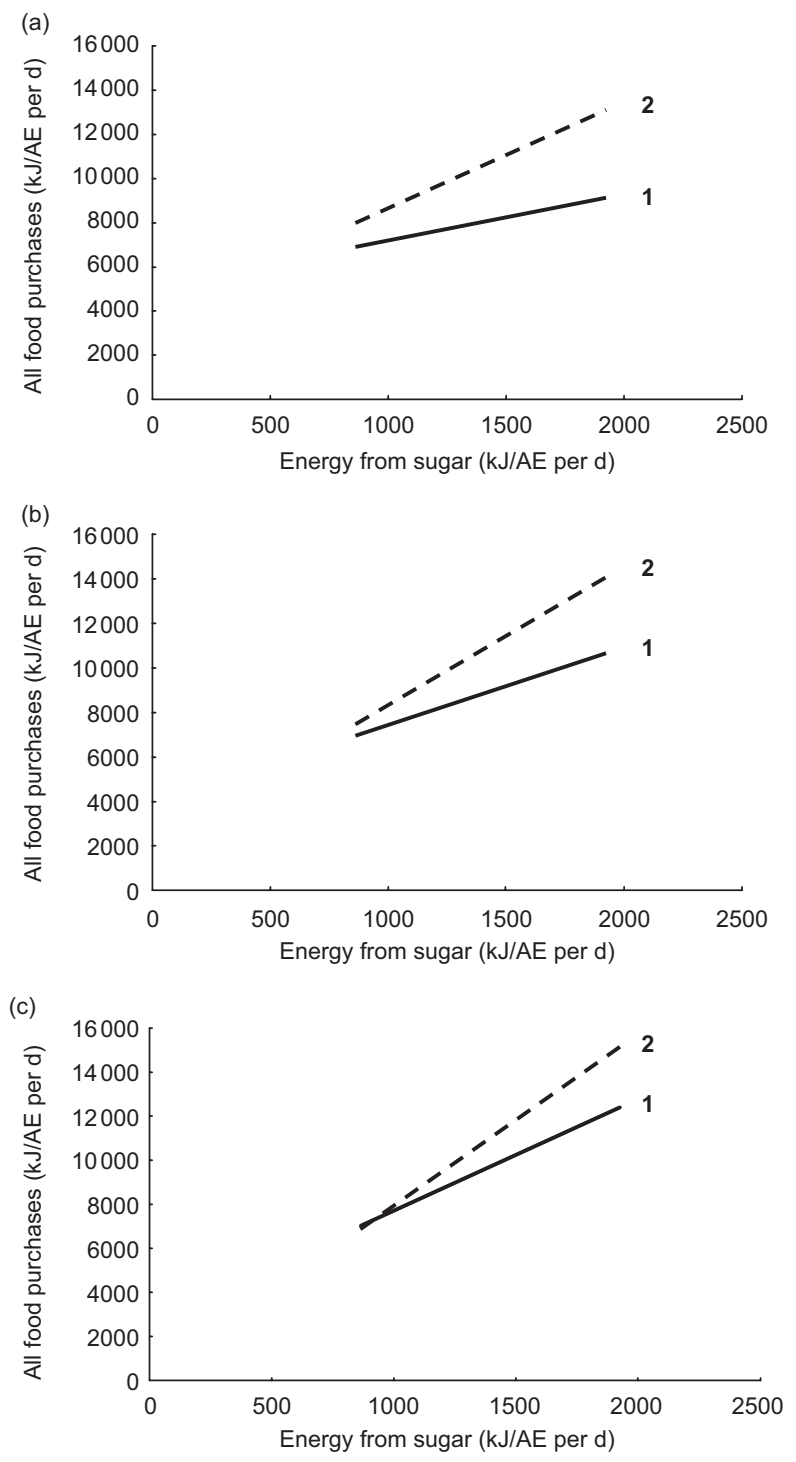

Fig. 1 Estimates based on the multiple linear regression model (with interactions) for the association between energy from sugar and total energy content of all food purchases, according to quintiles of the per capita household income distribution, contemplating two scenarios in terms of the percentage of total food expenditures on meals outside the home, Brazil, 2002-3: (a) lower income quintile; (b) middle income quintile; (c) upper income quintile. Scenario $1(-)$ : prediction done with per capita household income fixed at the mean income level of the lower, middle or upper quintile of the distribution of per capita household income, with the remaining explanatory variables in the model, except for energy from sugar, fixed at the mean value. Scenario $2(---)$ : prediction as for Scenario 1, but with the percentage of total food expenditures on meals outside the home fixed at zero. $\mathrm{AE}$, adult equivalent

strata, with a total energy content of food purchases far above the recommended $7998.00 \mathrm{~kJ} / \mathrm{d}$ intake in Brazil ${ }^{(19)}$.

Major limitations of the present study are related to the limitations of household budget surveys to accurately describe household food intake; that is, failure to consider both food eaten outside the home and the proportion of food purchased but not consumed by household members.
These limitations are compounded, in the case of the 2002-3 HBS, by the short duration (one week) of the reference period for collection of data on the food purchases made by each household.

In the present study, we attempted to control for the potential effect of food eaten outside the home by introducing, into the regression models, the percentage of total food expenditures on meals outside the home. We consider that, when also controlling for income, this percentage can be assumed to be a reasonable proxy for energy consumption outside the household.

Regarding food purchased but not consumed, it is initially reasonable to assume that this would occur to any relevant extent only among higher-income strata. Notwithstanding, in order for the relationship evidenced by the present study between sugar intake and total energy intake to be affected by the eventual wastage of food, it would be necessary for the non-consumed proportion of sugar to differ substantially from the non-consumed proportion of other foods.

To address the problem of the short reference period for data collection in each household, we adopted as units of analysis groups of households homogeneous as to geographic location and socio-economic characteristics, and which were studied in a uniform manner throughout the four trimesters of the year.

In favour of the relative accuracy of the HBS in assessing the contribution of sugar to the diet of the Brazilian population is the similarity between the proportion of energy from sugar found in the present survey $(16 \cdot 0 \%)$ and that estimated based on the country's food balance sheets for 2002-3 $(17 \cdot 7 \%)^{(3)}$.

Notwithstanding the limitations typical of household budget surveys, studies comparing their results with those of individual intake surveys have found considerable agreement between the two methods ${ }^{(20,21)}$. For example, a study carried out in four European countries showed a correlation coefficient of 0.74 between sugar intake as measured by a household budget survey and by an individual food consumption survey ${ }^{(20)}$. Certain authors even defend the hypothesis that, in the case of foods used as cooking ingredients such as sugar, household budget surveys may more accurately reflect actual intake than individual food intake surveys. This would be due to the difficulty of individuals in reporting the amount of intake of a food ingested as part of a recipe ${ }^{(21)}$.

Another limitation refers to the impossibility to examine separately the effect of sugar from beverages. There is growing evidence that sugared beverages in particular increase the risk of over-consumption of energy and thus of overweight and obesity ${ }^{(10,12,22)}$. In any case, as our data refer to food acquisition information, it is impossible to know in which form the sugar acquired by the household is going to be consumed.

Two strengths of the present study are the nationwide representativeness of the studied sample and statistical 
control for several sociodemographic characteristics that may act as confounders or effect modifiers in the association between energy from sugar and total energy content of food purchases. Regarding the latter, however, as in any other observational study, one cannot discard the possibility of influence by confounders not considered in the present analysis.

A population-based study carried out in the USA analysed the effect of sugar intake on total energy content of the diet of children aged 2 to 5 years. Analyses were stratified according to age, 2-3 years or 4-5 years, and children were classified into five groups according to the percentage contribution of sugar to the diet. The study reported a significant increase in total energy content in the diet of younger - but not older - children along with increases in the percentage contribution of sugar ${ }^{(14)}$. Another American study investigated the effect of total sugar in the diet (in this case, considering intrinsic sugars as well) on total energy content in the diet of children aged 10 years, but did not find any significant associations ${ }^{(23)}$. A population-based study in South Africa also showed that total energy intake was not significantly greater in the highest tertile of sugar intake, for which the average consumption was $57.9 \mathrm{~g}$ sugar/d (18.2\% of total energy intake $)^{(24)}$.

It is worth mentioning that studying the association between contribution of sugar (or any other food) in the diet and the diet total energy content - as was the case in the two American and the South African studies mentioned above - can be criticized for including total energy on both sides of the association equation ${ }^{(25)}$.

A 12-month prospective study carried out in the USA detected a significant association between soft drink consumption and weight gain among adolescents aged 9 to 14 years. These authors argue that a likely mechanism for this association is the increase in total energy content of the diet determined by soft drink intake, since the effect of soft drinks on overweight was strongly attenuated by controlling for total energy content in the diet ${ }^{(26)}$. A positive association between soft drink intake and weight gain or obesity, or even metabolic syndrome, especially among children and adolescents, has been shown by studies carried out in the USA and Canada ${ }^{(22-30)}$.

Brazilian studies directly evaluating the effect of sugar intake on total energy content, or even on overweight or obesity, will be required to confirm the results of the present study based on household food purchases. In any case, our results corroborate both international ${ }^{(1)}$ and national ${ }^{(19)}$ recommendations for population-wide reduction in the consumption of sugar.

\section{Acknowledgements}

This work received no funding to the authors or their institutions and there is no conflict of interest for any author. The three authors have participated substantially in the conception, design, data analysis and writing of the manuscript. R.B.L. wrote the initial drafts, R.M.C. reviewed all drafts and C.A.M. wrote the final version of the manuscript.

\section{References}

1. World Health Organization (2003) Diet, Nutrition and the Prevention of Chronic Diseases. Report of a Joint WHO/FAO Expert Consultation. WHO Technical Report Series no. 916. Geneva: WHO.

2. Popkin BM \& Nielsen SJ (2003) The sweetening of the world's diet. Obes Res 11, 1325-1332.

3. Food and Agriculture Organization of the United Nations (2004) FAO Statistics Database. http://faostat.fao.org/site/ 368/DesktopDefault.aspx?PageID $=368$ (accessed February 2009).

4. Food and Agriculture Organization of the United Nations (1998) Carbohydrates in Human Nutrition. Report of a Joint FAO/WHO Expert Consultation. FAO Food and Nutrition Paper Series no. 66. Rome: FAO.

5. Institute of Medicine (2002) Dietary Reference Intakes for Energy, Carbohydrate, Fiber, Fat, Fatty Acids, Cholesterol, Protein, and Amino Acids, pp. 1-43. Washington, DC: National Academies Press.

6. Anderson GH (1995) Sugars, sweetness, and food intake. Am J Clin Nutr 62, 1 Suppl., S195-S202.

7. Anderson GH \& Woodend D (2003) Consumption of sugars and the regulation of short-term satiety and food intake. Am J Clin Nutr 78, 4 Suppl., S843-S849.

8. Stubbs J, Ferres S \& Horgan G (2000) Energy density of foods: effects on energy intake. Crit Rev Food Sci Nutr $\mathbf{4 0}$, 481-515.

9. Rolls BJ \& Bell EA (2000) Dietary approaches to the treatment of obesity. Med Clin North Am 84, 401-418.

10. DiMeglio DP \& Mattes RD (2000) Liquid versus solid carbohydrate: effects on food intake and body weight. Int J Obes Relat Metab Disord 24, 794-800.

11. Ludwig DS (2002) The glycemic index: physiological mechanisms relating to obesity, diabetes, and cardiovascular diseases. JAMA 287, 2414-2423.

12. Van Wymelbeke V, Beridot-Therond ME, de La Gueronniere V \& Fantino M (2004) Influence of repeated consumption of beverages containing sucrose or intense sweeteners on food intake. Eur J Clin Nutr 58, 154-161.

13. Mattes R (2006) Fluid calories and energy balance: the good, the bad, and the uncertain. Physiol Behav 89, 66-70.

14. Kranz S, Smiciklas-Wright H, Siega-Riz AM \& Mitchell D (2005) Adverse affect of high added sugar consumption on dietary intake in American preschoolers. J Pedriatr 146, 105-111.

15. Instituto Brasileiro de Geografia e Estatística (1996) Tabela de composição de alimentos, $4^{\mathrm{a}}$ ed. Rio de Janeiro: Fundação IBGE.

16. Núcleo de Estudos e Pesquisas em Alimentação/Universidade Estadual de Campinas (2004) Tabela Brasileira de Composição de Alimentos - TACO: versão 1. Campinas, São Paulo: NEPA/UNICAMP.

17. US Department of Agriculture (2004) USDA Food Search for Windows, version 1.0, database version Standard Reference Release SR15. http://www.nal.usda.gov/fnic/ foodcomp (accessed March 2006).

18. Food and Nutrition Board (1989) Recommended Dietary Allowances, 10th ed. Washington, DC: Subcommittee on the 10th Edition of the RDAs, Food and Nutrition Board, Commission of Life Sciences, National Research Council.

19. Ministério da Saúde (2004) Guia Alimentar para a População Brasileira: promovendo a alimentação saudável. 
Brasília: Secretaria de Atenção à saúde, Departamento de atenção Básica, Coordenação-Geral da Política de Alimentação e Nutrição.

20. Naska A, Vasdekis VGS \& Trichopoulou A (2001) A preliminary assessment of the use of household budget survey data for the prediction of individual food consumption. Public Health Nutr 4, 1159-1165.

21. Becker W (2001) Comparability of household and individual food consumption data - evidence from Sweden. Public Health Nutr 4, 1177-1182.

22. Ludwig DS, Peterson KE \& Gortmaker SL (2001) Relation between consumption of sugar-sweetened drinks and childhood obesity: a prospective, observational analysis. Lancet 357, 505-508.

23. Farris RP, Nicklas TA, Myers L \& Berenson GS (1998) Nutrient intake and food group consumption of 10 -yearolds by sugar intake level: the Bogalusa Heart Study. J Am Coll Nutr 17, 579-585.

24. Steyn NP, Myburgh NG \& Nel JH (2003) Evidence to support a food-based dietary guideline on sugar consumption in South Africa. Bull World Health Organ 81, 599-608.
25. Forshee RA \& Storey ML (2004) Controversy and statistical issues in the use of nutrient densities in assessing diet quality. J Nutr 134, 2733-2737.

26. Berkey CS, Rockett HRH, Field AE, Gillman MW \& Colditz GA (2004) Sugar-added beverages and adolescent weight change. Obes Res 12, 778-788.

27. Dubois L, Farmer A, Girard M \& Peterson K (2007) Regular sugar-sweetened beverage consumption between meals increases risk of overweight among preschool-aged children. J Am Diet Assoc 107, 924-934.

28. Ebbeling CB, Feldman HA, Osganian SK, Chomitz VR, Ellenbogen SJ \& Ludwig DS (2006) Effects of decreasing sugar-sweetened beverage consumption on body weight in adolescents: a randomized, controlled pilot study. Pediatrics 117, 673-680.

29. Dhingra R, Sullivan L, Jacques PF, Wang TJ, Fox CS, Meigs JB, D'Agostino RB, Gaziano JM \& Vasan RS (2007) Soft drink consumption and risk of developing cardiometabolic risk factors and the metabolic syndrome in middle-aged adults in the community. Circulation 116, 480-488.

30. Drewnowski A \& Bellisle F (2007) Liquid calories, sugar, and body weight. Am J Clin Nutr 85, 651-661. 